\title{
Socio-Economic Indicators of Mining Regions Development
}

\author{
Sergey Kukushkin ${ }^{1, *}$, Oleg Kalenov², and Raisa Kamanina ${ }^{3}$ \\ ${ }^{1}$ Plekhanov Russian University of Economics, Academic Department of Organizational and \\ Managerial Innovations, 117997, Moscow, 36 Stremyanny lane, Russia \\ ${ }^{2}$ Plekhanov Russian University of Economics, Academic Department of Industrial Economics, \\ 117997, Moscow, 36 Stremyanny lane, Russia \\ ${ }^{3}$ Moscow University for Industry and Finance «Synergy», Academic Department of Commerce and \\ Trade, 125190, Moscow, 80 Leningradsky Prospekt, Russia
}

\begin{abstract}
The paper analyzes the dynamics of socio-economic indicators of the development of coal-mining regions of Russia. The aim of the study is to analyze the socio-economic situation of coal-mining regions and determine the factors that influenced the social processes in the region. Based on statistical data for the period from 2010 to 2019, there was conducted the analysis of changes in economic indicators such as: income of the population; gross regional product per capita; nominal average monthly wage; unemployment rate; the proportion of the population with incomes below the subsistence level; housing commissioning in the regions. Analysis of the data showed that the most favorable social position of all the analyzed coal-mining regions is observed in the Sakhalin region. The "outsiders" in terms of social status among the coal-mining regions are the Trans-Baikal Territory and the Kemerovo Region. Improvement of the social situation in coal-mining regions is associated with the adoption by the Russian Government of a program to combat poverty, an increase in social payments to certain categories of citizens, an indexation of old-age pensions, etc. It was also revealed that social processes in the regions are influenced by prices for hydrocarbons on the world market and objective economic phenomena such as business cycles.
\end{abstract}

\section{Introduction}

The development of the region is reflected in the final social indicators. The measurement of social processes can be characterized by the dynamics of social and economic indicators, with the help of which they receive both indirect (but very important) and direct information about the nature and content of social processes. Analysis of social indicators and variables is important for the study of social processes in mining region. Together with statistical data, they characterize the real changes in social processes in the region. A variety of indicators can be considered as indicators of socio-economic development:

\footnotetext{
* Corresponding author: oekalenov@yandex.ru
} 
- an increase in the income of the population;

- an increase in social payments;

- reducing the level of poverty;

- the number of educational institutions of both general and vocational education;

- the number of healthcare organizations, etc.

Most often, the group of the studied indicators is determined depending on the goals of the study and the development goals of the region.

\section{Materials and Methods}

Various issues of socio-economic development of mining regions are considered in the works of such researchers as: N. Amirova [1], S. Zhironkin [2], A. Voloshin [3], E. Dotsenko [4], N. Ezdina [5], V. Frolova [6], N. Kazitskaya [7], L. Khayrulina [8], I. Politkovskaya [9], N. Rebrowa [10], etc.

The informational functions of social indicators are defined by the American researcher E. Carlisle - as the value of the operational dimension within the framework of a certain concept, which makes it possible to form an information system that characterizes separately each of the social processes and the social system as a whole [11]. The social indicators system provides information for solving the following tasks:

- assessment of the degree of possibility of realizing the goals of social development;

- the influence of social processes on changes in society, which are not provided for by the programs and decisions of the regional administration;

- comparison of the actual results obtained with the planned ones and, if necessary, making corrective decisions.

Economic (socio-economic) indicators provide an opportunity to obtain information:

- about changes in the material and cultural wealth of the community for each individual person;

- for medium-term planning and development of long-term programs.

The system of economic indicators characterizes the level of development of social processes and is divided into the following groups:

- population and labor resources;

- national wealth, production and circulation of the social product;

- change in national income, in the framework of the study - gross regional product (GRP);

- material well-being of the population, etc.

This study analyzes the dynamics of the following economic (socio-economic indicators) indicators of coal-mining regions:

- dynamics of per capita GRP;

- the size of the real disposable cash income of the population;

- the size of the real average monthly wage per employee;

- the total number of unemployed at the end of the reporting period, taking into account officially registered unemployed persons;

- the share of the population in the total number, whose incomes are below the established subsistence level;

- the level of commissioning of residential real estate.

\section{Results and Discussion}

The gross regional product is a generalized indicator of the economic activity of the region, which characterizes the production of end-use products. In addition, this indicator 
characterizes the gross value added generated by the residents of the region. GRP is determined at current and basic prices.

Determining the average per capita GRP makes it possible to study the dynamics of economic growth with a simultaneous comparison of this indicator in other regions. Thus, it is possible to obtain an indirect estimate of the level of well-being in the regions.

According to the graph shown in Fig. 1, the highest per capita income for the analyzed period among the coal-mining regions is observed in the Sakhalin region, the lowest in the Trans-Baikal Territory. The dynamics of the increase in per capita GRP is also observed in the Sakhalin Oblast, at the same time in the period 2016-2017, there is a sharp decrease in this indicator. The dynamics of this indicator in the other six analyzed regions is smoother and more predictable.

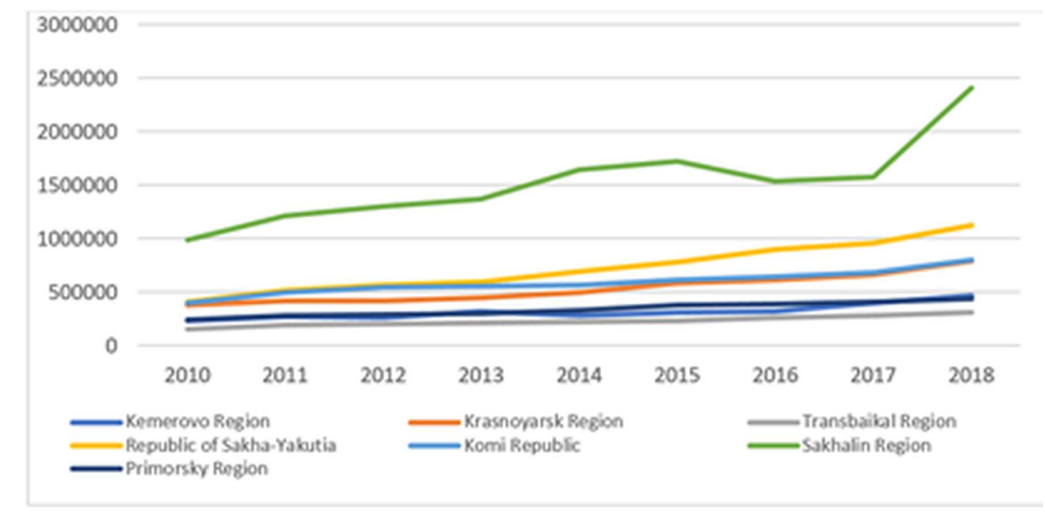

Fig. 1. Dynamics of per capita GRP (RUB / person) [12].

However, the dynamics of GRP per one average resident of the region, showing the number of products produced in value terms per person, gives only an approximate idea of the welfare in the region. This is due to the fact that a number of important factors are not involved here, including the following [13]:

- the distribution of income between the inhabitants of the region is not taken into account. There may be a significant difference in the share of the middle class or in the share of the poor, since the real part of the regional income may be concentrated in the hands of a narrow group of the population;

- statistical data on the production of added value in the region do not take into account the availability and quality of consumer and social benefits, as well as the degree of militarization and monopolization of the economy.

More objectively, the level of well-being of residents of the regions can be shown by the following indicators:

- real incomes of the population (Fig. 2);

- the size of the nominal average monthly wage (Fig. 3);

- the share of the population in the total number, whose incomes are below the established subsistence minimum (Fig. 4). 


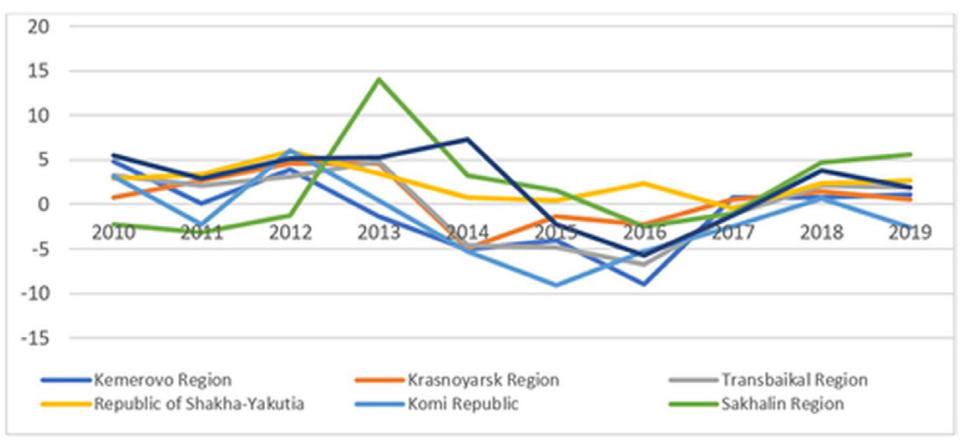

Fig. 2. The rate of change in the real disposable money income of the population (in $\%$ of the previous year) [12].

As can be seen from the graph in Fig. 2, the rates of change in the analyzed regions were relatively low or had a mostly negative value. They were especially low in the Kemerovo region in the period from 2014 to 2016. Against 2013, in 2014 amounted to $94.5 \%$, in 2015 against $2014-95.9 \%$. The drop in income in 2016 (against 2015) was especially significant $-91.0 \%$. The same situation was in the Komi Republic - in 2014 compared to 2013, real incomes amounted to $94.7 \%$; in 2015 (against 2014) $-90.9 \%$ and in 2016 (against 2015) - 94.7\%. In subsequent years, incomes in these regions increased slightly. So in the Kemerovo region, the annual growth was about $1 \%$, and in the Komi Republic, the growth was observed only in 2018, real incomes in the republic in relation to 2017 amounted to $100.7 \%$. It was more successful in the analyzed period in the Sakhalin region. There was a more significant increase in the real income of the population, especially in 2014 (against 2013), the increase in income was 14\%. At the same time, a decrease in the income of the population in the region was observed in $2017(-2.5 \%$ compared to 2016$)$ and in 2018 ( $-1 \%$ compared to 2017$)$.

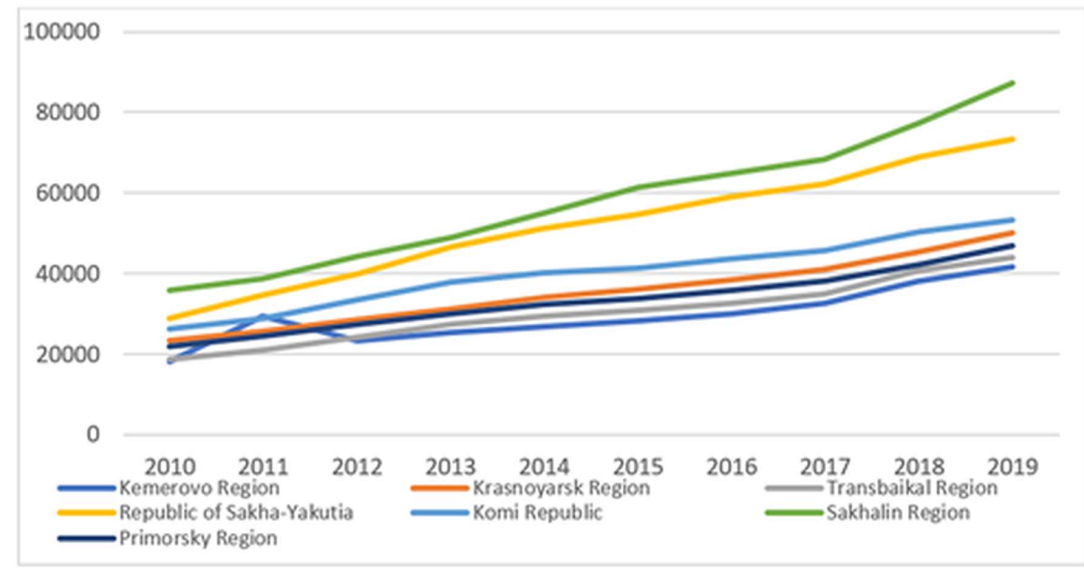

Fig. 3. Nominal average monthly wage per employee (RUB) [12].

In mid-April 2021, the Press Service of Rosstat made a statement that in Russia, according to preliminary results, per capita income for 2020 increased by $2.94 \%$. In 4th quarter 2019, they amounted to RUB 41,328, and in 4th quarter 2020 they reached the level of RUB 42,543. Rosstat also notes that in 2020 in the 4th quarter compared to the 3rd quarter, income from property increased by $34.6 \%$, and income from business and other production activities increased by $22.5 \%$. 
As for wages (which, as you know, are the main part of the real incomes of the majority of the population), the opposite situation is observed here. As can be seen from the graph in Fig. 3, in all coal-mining regions, there was a steady increase in nominal wages. The highest wages were observed in the Sakhalin Oblast. If in 2010 in the region it was 35,848 RUB, then in 2019 it already amounted to 87,418 RUB, an increase of $243.86 \%$. The lowest nominal wages were in the Kemerovo region. In 2010, it was slightly more than 18,000 RUB, in 2019 -- 41,770 RUB, an increase of $231.7 \%$. A similar situation was observed in other coal-mining regions of the country. According to Rosstat, in 2020 the average monthly wage increased by $8.44 \%$ (4,360 RUB): from 51,684 RUB up to RUB 56,044 . The old-age pension has also increased from 15,966 RUB up to 16,790 RUB, an increase of $5.16 \%$.

From the analysis of the data presented in the graphs in Figs. 2 and 3, it can be concluded that, despite a significant increase in nominal wages, income from other sources has sharply decreased.

The next important indicator characterizing the well-being of the inhabitants of the region is the size of the population whose incomes are below the subsistence level. The most prosperous region according to this indicator is the Sakhalin Region: since 2013, the specific population with low incomes has been steadily decreasing. If in the period from 2010 to 2012 , the share of this population group was more than $11 \%$ (in $2010-11 \%$, in $2011-11.9 \%$ and in $2012-11.8 \%$ ), then in the subsequent period it steadily decreased and was at the level of less than $10 \%$ (in $2013-9.9 \%$, in $2014-9.7 \%$, in $2015-10.0 \%$, in $2016-9.9 \%$, in $2017-9.2 \%$, in $2018-8.5 \%$ and in $2019-8.2 \%$ ).

The most difficult situation is observed in the Trans-Baikal Territory. This region has the highest proportion of the population whose incomes are below the subsistence level. The dynamics of this indicator can be divided into three stages. At the first stage, from 2010 to 2013 , there is a decrease in the share of this population group from $19.0 \%$ in 2010 to $16.9 \%$ in 2013 ; the second stage (2014-2015) - a sharp increase, in $2014-18.8 \%$ and in $2015-21.3 \%$. The third period is characterized by an unstable decline. So the share of the poor in the region in 2016 was $22.1 \%$ and in $2019-21.5 \%$.

According to the Press Service of Rosstat, the number of poor citizens of Russia in 2020 decreased to 17.8 million people. At the same time, the number of poor people in the 4 th quarter of 2020 compared to the 3 rd quarter of the same year decreased from 18.8 million people to 13.5 million people (from $12.8 \%$ to $9.2 \%$ ).

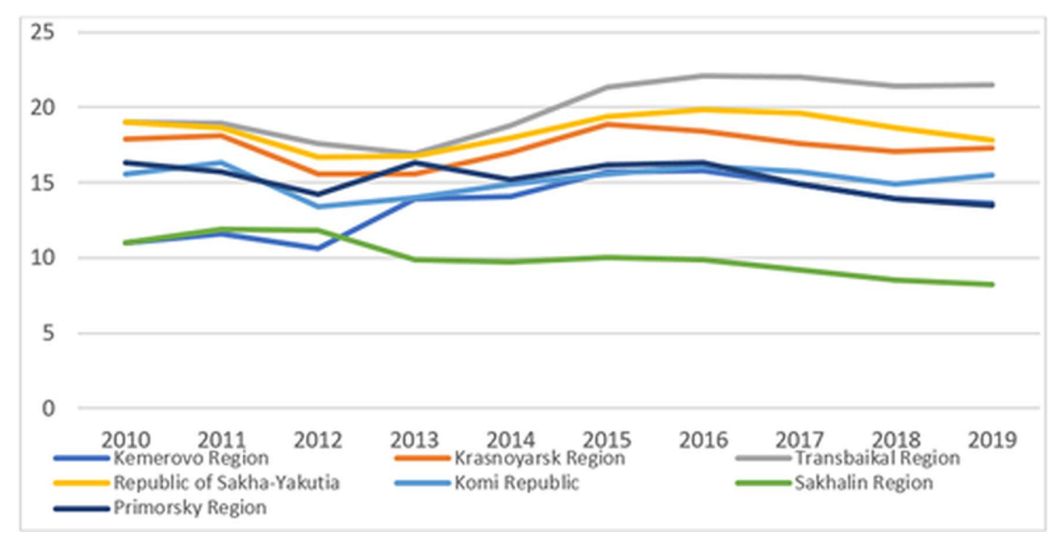

Fig. 4. The proportion of the population in the total number, whose incomes are below the established subsistence minimum (in \% of the total number of the subject) [12]. 
The decrease in the poverty level, according to Rosstat, was due to the following reasons:

- an increase in average per capita income;

- growth in average monthly nominal wages and old-age pensions;

- implementation of social programs. Therefore, in the fourth quarter of 2020, 3.4 trillion RUB were paid for social needs (the increase was 5.9\%); families with children received 110.5 billion RUB, the unemployed - 15.9 billion RUB.

An important indicator characterizing the socio-economic situation in the region is the unemployment rate (Fig. 5). The lowest unemployment rate is observed in the Sakhalin Oblast. In 2010, 3.1 thousand people were officially registered in the region (or $1.06 \%$ in relation to the average annual number of employed), and 1.3 thousand people. $(0.47 \%$ of the employed) - in 2019.

The highest unemployment rate of the seven analyzed regions for the period from 2010 to 2019 was observed in the Kemerovo region (Fig. 4). The dynamics of this indicator in the region is ambiguous; three periods can be distinguished. In the first period from 2010 to 2013 - a sharp decline in the unemployment rate. If in 2010 the level of this indicator was 37.6 thousand people or $2.93 \%$ of the number of employed, then in 2013 there were 24.9 thousand registered unemployed people (1.91\% of the total number of employed). In the second period (2014-2015), there is a sharp increase: if in 2014 there were registered unemployed - 28.2 thousand people $(2.21 \%)$, then in 2015 the number of unemployed amounted to 36.2 thousand people. In relative terms (2.95\% of the employed), it exceeded this level in 2010, i.e. year of the beginning of observation. In the third period (from 2016 to 2019), there is initially a slight decrease: in 2016, 34.1 thousand people were registered ( $2.79 \%$ of the employed). This was followed by a sharp decline in this indicator - in 2019 , 18.2 thousand people were registered (1.55\% of the employed).

In general, in 2015-2016 practically in all analyzed regions (with the exception of the Sakhalin Oblast) there is an increase in the number of unemployed. There can be three reasons: 1) the effect of economic sanctions against Russia, which affected the economies of the regions; 2) the transition to the policy of import substitution; 3) a decrease in the price of a barrel of oil on the world market, which led to a decrease in demand for coal and a decrease in its price, and, as a consequence, an increase in unemployment.

An important indicator characterizing the socio-economic situation in the region is the indicator of the construction of residential real estate and the provision of housing for the residents of the region. According to the French economist T. Piketty, the growth of capital accumulation, including in the form of property (and in particular, housing property) characterizes the stability of the country's economy as a whole (and, consequently, of an individual region), and for each individual person - stability and guarantees of its future. In his opinion, the ratio of capital to per capita income should be $1 / 50$, in other words, there should be 50 RUB of capital per ruble of a person's income [14]. 


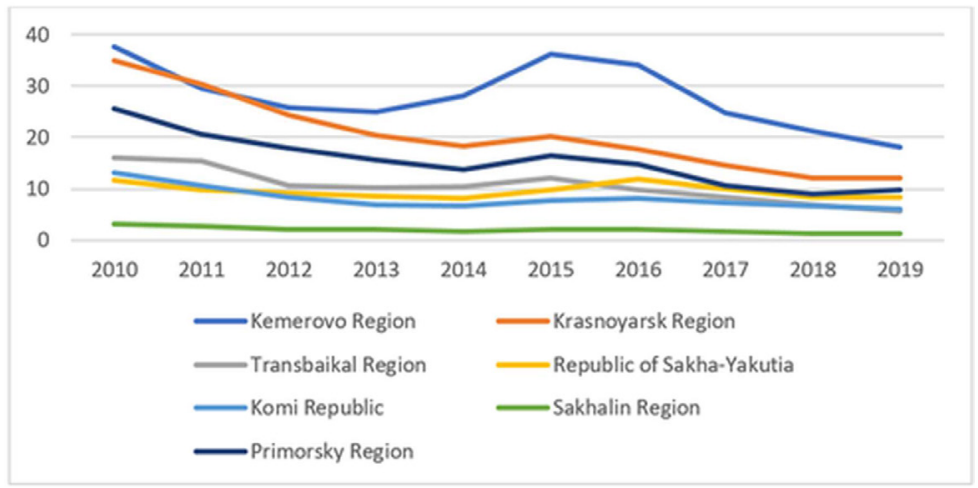

Fig. 5. The total number of unemployed (thousand people) [12].

Figure 6 shows the schedule of housing commissioning in coal-mining regions for the period 2010-2019. The highest level of housing commissioning is observed in the Sakhalin Oblast. If in 2010, $404 \mathrm{~m}^{2}$ per 1000 people were commissioned in the region, then in 2019 $678 \mathrm{~m}^{2}$ was already commissioned (an increase of $67.8 \%$ ). But even in this relatively prosperous region (judging by other socio-economic indicators), there were "breakdowns". So, in 2013, $435 \mathrm{~m}^{2}$ of housing per 1000 people was commissioned (a drop in relation to 2012 was almost $10 \%$ ), in $2018-541 \mathrm{~m}^{2}$ compared to $711 \mathrm{~m}^{2}$ in 2017 (a decrease of $31.4 \%)$.

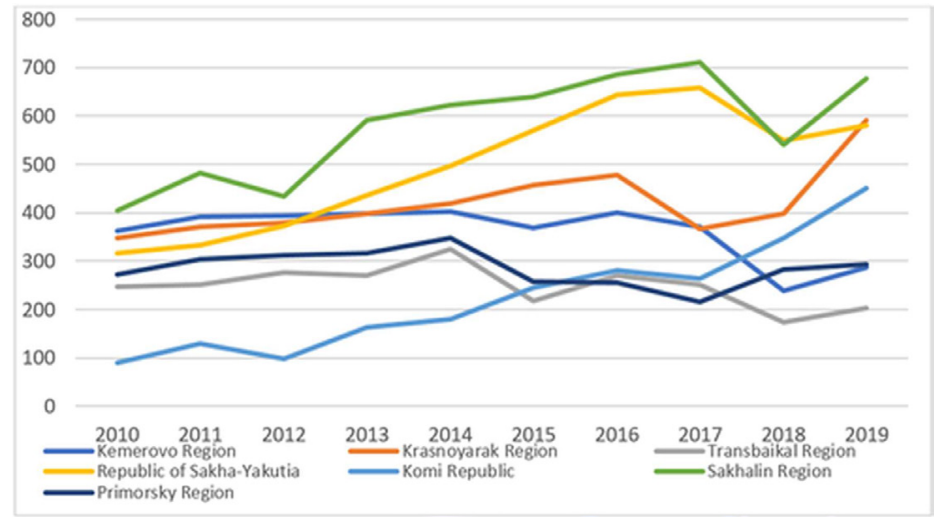

Fig. 6. Commissioning of residential buildings for 1000 people $\left(\mathrm{m}^{2}\right.$ in the total area of residential premises) [12].

As for other coal-mining regions, the most impressive growth in housing commissioning is observed in the Komi Republic. If in 2010 in the republic $89 \mathrm{~m}^{2}$ was commissioned per 1000 people (the last place out of the seven analyzed regions), then in 2019 the commissioning of housing per 1000 people amounted to $450 \mathrm{~m}^{2}$. The growth is $405.62 \%$, which allowed this region to move to the fourth place among coal-mining regions.

The lowest dynamics of housing commissioning is observed in the Trans-Baikal Territory and the Kemerovo Region. If in $2010248 \mathrm{~m}^{2}$ was commissioned in Transbaikalia, then in $2018-174 \mathrm{~m}^{2}$, in $2019-204 \mathrm{~m}^{2}$. The decrease in 2019 compared to 2010 was $17.74 \%$. Kemerovo Oblast in 2010 occupied the second place out of seven in terms of housing commissioning per 1000 people, housing commissioning amounted to $362 \mathrm{~m}^{2}$. In 
2019, $287 \mathrm{~m}^{2}$ were commissioned in the region (a decrease of 26.1\%). Upon commissioning of housing in 2019 , the region moved to the penultimate place out of seven.

In general, it should be noted that the commissioning of housing was "disastrous" in 2018 (with the exception of the Komi Republic) for all coal-mining regions. It is quite possible that this is due to the peculiarities of the construction economic cycle.

\section{Conclusion}

Based on the analysis performed, the following conclusion can be drawn. The most favorable socio-economic situation is observed in the Sakhalin region. The region occupies a leading position in almost all analyzed indicators. By most indicators, the regionsoutsiders are the Kemerovo Region and the Trans-Baikal Territory.

It should also be noted that in 2019 , there is a positive trend in the analyzed economic indices in the coal-mining regions. This is due to the poverty reduction program adopted by the Russian Government in May 2019. This program provides for indexation of old-age pensions, increasing the living wage to the minimum wage,; payment of social benefits to certain categories of citizens. Corresponding programs have been adopted in Russian regions. Of course, COVID-19 and the pandemic have made their own adjustments to most government programs, including those to combat poverty. But in the Letter to the Federal Assembly Russian Federation, specific measures are outlined to improve the social situation of Russians, taking into account the current situation.

\section{References}

1. N. Amirova, L. Sargina, A. Khasanova, E3S Web Conf. 174, 02011 (2020)

2. S. Zhironkin, J. Janocko, S. Demchenko, Y. Suslova, O. Zhironkina, E3S Web Conf. 174, $04020(2020)$

3. S. Zhironkin, A. Voloshin, O. Zhironkina, S. Vöth, G. Kayachev, E3S Web Conf. 174, 04011 (2020)

4. E. Dotsenko, N. Ezdina, A. Khasanova, M. Khasanov, E3S Web Conf. 247, 01068 (2021)

5. E. Dotsenko, N. Ezdina, A. Khasanova, M. Khasanov, E3S Web Conf. 247, 01069 (2021)

6. V. Frolova, O. Dolina, T. Shpilkina, E3S Web of Conf., 174, 04025 (2020)

7. N. Kazitskaya, V. Prusova, S. Bochkov, E3S Web of Conf., 174, 04045 (2020)

8. L. Khayrulina, D. Savrasova, M. Zhidkova, E3S Web of Conf., 174, 04048 (2020)

9. I. Politkovskaya, D. Khvichiya, L. Artamonova, E3S Web of Conf., 174, 04047 (2020)

10. N. Rebrowa, A. Kovalev, O.V. Frik, G. Sargsyan, E3S Web of Conf., 174, 04054 (2020)

11. B. Bauer, Social Indicators (CU Press, Cambridge, 1966)

12. Official site of the Federal State Statistics Service of the Russian Federation. URL: http://www.gks.ru/

13. V.V. Savaley, Bulletin of the Vladivostok University of Economics and Service 9(2), 31-41 (2017)

14. T. Piketty, Capital in the XXI century (Ad Marginem Press, Moscow, 2016) 